\title{
LOGOTERAPIA PARA PAREJAS: UNA PROPUESTA ANTROPOLÓGICA, METODOLÓGICA Y ACTITUDINAL
}

\section{Resumen}

En este artículo se brinda una perspectiva de la psicoterapia de pareja desde una orientación humanista - existencial - fenomenológica, específicamente desde la mirada de la logoterapia y el pensamiento de Viktor Frankl. Este representa un intento por entender al ser humano como un ser que es relación, y en la posibilidad de realizar un verdadero encuentro con un otro, fundado en una actitud existencial de apertura y autenticidad, esto es, estar dispuesto al mundo, al Tú que se presenta amable, apropiándose del riesgo de ser genuino y dejarse tocar por todo lo valioso que puede encontrarse y realizarse en el vínculo, que es lo que ocurre entre un Yo y un Tú. La comunicación es entendida como el fundamento de la relación, constituyéndose en pieza clave de trabajo para comprender la dinámica de la pareja. Así mismo se desarrolla una mirada libertaria de las relaciones humanas, que subraya la individualidad y la responsabilidad como bases para formar la comunidad en pareja, y con una visión axiológica de la relación que contempla valores que al ser vivenciados pueden contribuir a que la vida tenga más sentido. Del mismo modo se desarrolla una propuesta terapéutica sostenida en la fenomenología como metodología y actitud frente a la pareja, un diálogo socrático entre tres, que busca el despliegue de lo espiritual en la pareja en términos de autodistanciamiento y autotrascendencia, para así ser más conscientes de la forma como se relacionan y asuman el riesgo de decidirse por alguna posibilidad, quizá de salir al encuentro del otro y vivir una relación más satisfactoria.

Palabras claves: Psicoterapia de pareja, logoterapia, humanismo, existencialismo, fenomenología, diálogo socrático, Viktor Frankl.

\begin{abstract}
In this article, we provide a perspective on couple psychotherapy from a humanistic - existential phenomenological orientation, specifically from the perspective of logotherapy and the thinking of Viktor Frankl. This represents an attempt to understand the human being as a being that is a relationship, and in the possibility of making a truly encounter with another, based on an existential attitude of openness and authenticity, which mean, to be willing to the world, to You who presents as kind person, appropriating the risk of being genuine and letting himself be touched by all the valuable things that can be found and realized in the bond, which is what happens between a Self and a You. Communication is understood as the foundation of the relationship, constituting a key piece of work to understand the dynamics of the couple. Likewise, a libertarian view of human relations is developed, which emphasizes individuality and responsibility as the basis for forming a community as a couple, and with an axiological vision of the relationship that contemplates values that, when experienced, can contribute to life having more sense In the same way, a therapeutic proposal sustained in phenomenology is developed as a methodology and attitude towards the couple, a Socratic dialogue between three, which seeks the unfolding of the spiritual in the couple in terms of self-distance and self-transcendence, in order to be more aware of the way they relate and assume the risk of deciding for some possibility, perhaps to go out to meet the other and live a more satisfying relationship.
\end{abstract}

Key words: Couple psychotherapy, logotherapy, humanism, existentialism, phenomenology, socratic dialogue, Viktor Frankl.

* Psicólogo. Docente Universidad Femenina del Sagrado Corazón. asalomon@cpllogoterapia.com https://orcid.org/0000-0002-5147-1270 


\section{UN MISTERIO LLAMADO RELACIÓN}

El ser humano es un ser que, más que relacionarse, es relación. Relación con el mundo, con los otros, con las cosas, consigo mismo. Siempre hay un algo, o un alguien con quien ser. Sin embargo en este mundo vincular hay ciertas relaciones que revelan la condición humana de ser - con - otros, la posibilidad de realizarse en el encuentro auténtico con un Tú y también de vivir el desencuentro, la posibilidad de abrirse y dejarse ver por el otro, así como cerrarse e impedir su clara mirada. La libertad humana se muestra aquí en su forma más sublime: la elección, pues la forma de ser con la otra persona es una actitud que se elige y una responsabilidad que se asume, y dependiendo de esta actitud podremos vivir una relación auténtica donde predomina el encuentro, o una relación neurótica donde predominan la inautenticidad y el sufrimiento innecesario. Sin embargo todo lo humano es imperfecto, por ende no hay relación humana en la que todo sea autenticidad. El objetivo de un proceso psicoterapéutico de orientación logoterapéutica no es necesariamente que la pareja permanezca junta, sino que puedan ser más conscientes de cómo viven su relación, de sus actitudes y formas de ser con el otro, del para qué de sus intenciones y conductas, de que tanto eligen dejarse ver y tocar afectivamente por el compañero, de qué tanto logran ver a ese otro como un legítimo otro, o de qué tanto co-construyen un proyecto en común que de sentido a sus vidas. A partir de toda esta comprensión mutua sigue la elección de qué hacer con la relación. De todo esto hablaremos a continuación, revisando la antropología frankleana acerca de las relaciones y el amor, así como los factores clave que influyen en la calidad del vínculo, como la calidad de la comunicación, la responsabilidad y la madurez en el amor.

\section{UNA ANTROPOLOGÍA DE LAS RELACIONES HUMANAS: LA PROPUESTA DE LA LOGOTERAPIA}

\section{Visión del ser humano desde Viktor Frankl}

Toda psicoterapia descansa en una antropología (Frankl, 2007), es decir, en una visión del ser humano. En este sentido la antropología frankleana nos aporta conceptos clave para poder comprender esta perspectiva de la persona humana como ser existencial
- relacional y así poder delinear una mirada de las relaciones de pareja y su intervención terapéutica.

El primer concepto clave es la libre voluntad, entendida como la capacidad específicamente humana para tomar decisiones y configurar la propia existencia. Según Max Scheler (1957) lo espiritual en el ser humano, es decir, todo lo que hay de libre en la persona, desde donde puede tomar una postura ante cualquier condicionamiento ya sea psíquico, biológico o social (Frankl, 2007). Esta libertad viene aunada a la responsabilidad como dos caras de una misma moneda (Frankl, 2013), ya que tener ese margen de libertad personal nos invita a poder elegir las respuestas ante la vida. De ahí que para la logoterapia el hombre es profundamente responsable por lo que puede hacer de sí mismo, aunque no siempre controle sus circunstancias, bien puede decidir cómo afrontar lo que le toca vivir. Siendo así, la persona tiene la capacidad para elegir con quien se relaciona, es más, siempre elige libremente a la pareja, siendo este uno de los puntos clave a tratar en el proceso terapéutico. Si bien esta elección es siempre en libertad, no siempre es con libertad, ya que muchas veces nuestras elecciones son en gran medida inconscientes y desde el instinto, como alguien con dependencia emocional que no sabe cómo elige ni para qué elige a la pareja. Esta persona elige sin consciencia ni responsabilidad, empujada por el impulso a estar con alguien, prisionera de su instinto de supervivencia afectiva. La decisión responsable implica un despliegue de libertad a otro nivel, es cuando hablamos de lo que Frankl llama libertad para (Frankl, 2007). Según el psiquiatra austriaco, la elección auténtica de pareja es un despliegue de la libre voluntad hacia un otro que se presenta y al cual podemos contemplar en su unicidad. El amor es para Frankl un acto intencional.

El segundo concepto es la voluntad de sentido, esta constituye el motor que mueve a cada persona a encontrar sentido a su vida (Frankl, 2002). Según Frankl la principal motivación humana es encontrar aspectos valiosos en la vida, cuya percepción y realización conlleva a la vivencia del sentido (Salomón y Díaz del Castillo, 2019), a diferencia de la postura psicodinámica de Freud donde la principal motivación es la búsqueda de distensión, a lo que Frankl llamó voluntad de placer, y la postura 
de la psicología individual de Alfred Adler donde la principal motivación es no sentirse inferior, a lo que Frankl llamó voluntad de poder. Para el padre de la logoterapia ambas son visiones reduccionistas del ser humano desde lo puramente biológico instintivo, por lo que intentó ofrecer una mirada rehumanizante que contemple los fenómenos humanos en su real dimensión.

El tercer concepto es el sentido, que podríamos entender como la percepción afectiva de valores en diversos contextos y que al realizarlos confieren sentido a la vida (Salomón y Díaz del Castillo, 2019). Como para Frankl los valores esperan por la persona en el mundo, este sentido es algo que se encuentra en la vida misma, que es por decirlo así "afuera" de la persona y no algo intrapsíquico. De ahí que podamos encontrar y realizar valores en lo que podemos dar al mundo, como el trabajo o el servicio en relación más o menos grande con la comunidad (Frankl, 2013); además en las experiencias donde recibimos del mundo algo significativo, como en los vínculos, un encuentro amoroso y el contacto con la naturaleza; y en la actitud frente a las situaciones límite que nos suscitan sufrimiento. De esta manera, es el segundo camino el que nos corresponde trabajar, es decir, la vivencia de valores en los vínculos, en el encuentro con otra persona con amor, algo que aporta sentido a la vida.

\section{El ser relación: Yo - Tú y la perspectiva existencial fenomenológica}

La antropología frankleana nos brinda una mirada relacional de la existencia humana. Esto significa que el ser humano entendido como consciencia nunca es un Yo aislado, sino siempre parte de lo que podríamos llamar un binomio (Buber, 1979), donde el Tú es un aspecto del ser relación, es decir, un Yo - Tú. Siendo así toda existencia es siempre relación, ya sea con un otro legítimo o con una cosa, a este segundo tipo de relación la llamamos Yo - ello (Buber, 1979). Y si pensamos bien el asunto, nos encontramos con esa realidad existencial, pues siempre estamos en relación con el mundo, con otras personas o con las cosas, sin poder aislarnos del todo. Así Frankl retoma una mirada dialógica de la existencia, que pone el énfasis no en la persona como un individuo solitario que entra en relaciones, sino como un ser que si bien es singular y único, nunca deja de ser relación con los demás. La relación Yo - Tú tiene ciertas características que nos llaman a la reflexión terapéutica, pues una relación recíproca de persona a persona es una relación donde no se tiene a nadie como quien tiene un objeto, no hay posesión alguna ni utilidad (Buber, 1979), es decir, el Tú no me sirve como una cosa útil, algo que sí puede observarse en los aspectos neuróticos o inauténticos de una relación y es objeto de trabajo terapéutico desde la logoterapia.

Así mismo encontramos esta mirada relacional frankleanaen la perspectiva existencial fenomenológica de la filosofía, donde la persona y su mundo conforman una unidad. Por ejemplo para Edmund Husserl la conciencia es siempre conciencia de algo y esto revela la naturaleza relacional del ser humano (Martínez, 2013), a lo que llamó intencionalidad. Para Martin Heidegger el ser humano es un ser - en - el - mundo, lo que hace referencia a una disposición particular del ser, un estar ahí, que revela que existir es ser - con - los - otros (Heidegger, 2009) en una inescindible unidad. El quid del asunto reside entonces en la actitud con la cual somos relación con el Tú, con el otro que se nos presenta como un otro legítimo al cual podemos reconocer y confirmar en su singularidad y novedad, en su ser único e irrepetible, no solo en su actualidad sino en sus posibilidades, un ser que no está acabado sino que viene siendo y que puede llegar a ser una mejor versión de sí mismo. A esta capacidad la llamó Frankl autotrascendencia, esto es ir más allá de uno mismo al encuentro de lo valioso que hay en el mundo, en este caso, del amado. La actitud contraria implica un estar cerrado al mundo, no dejarse ver por el otro ni alcanzar a verlo en su totalidad, sino solo en facetas, con un significado utilitario y de posesión característico de la neurosis, algo que es importante comprender y trabajar en el proceso terapéutico.

El sentido del amor: los valores de experiencia

Nos dice Viktor Frankl que el amor es fuente de sentido para la vida. Esto a través de la relación con una otra persona, con un Tú, a lo que nombró como valores de experiencia. Estos valores se vivencian en la medida en que la persona se atreve a encontrarse con la pareja, desde los momentos iniciales del irse conociendo hasta ir consolidando un vínculo donde predominen la comunicación, la confianza y el amor. 
En este sentido el amor es "la vivencia de otro ser humano, en todo lo que su vida tiene de peculiar y singular" (Frankl, 2013), donde el Tú es contemplado en su ser - así - y - no - de - otro - modo por un Yo, en su ser insustituible e irremplazable, sin mérito alguno, sino como una cuestión de gracia (Frankl, 2013). Esta vivencia del amor sensibiliza a la persona frente a los valores, en una suerte de apertura al mundo, una resonancia afectiva que se da en la entrega del Yo hacia el Tú, donde se trasciende, se intenciona hacia ese otro amado, así "el cosmos entero del Yo amante gana profundidad de valor, resplandece bajo la luz brillante de aquellos valores que solo el enamorado acierta a ver, pues el amor no hace al hombre ciego, como a veces se piensa, sino que, por el contrario, le abre los ojos y le agudiza la mirada para percibir los valores" (Frankl, 2013 p. 198).

Pero, ¿Qué es el amor para Viktor Frankl? Es el acto intencional que nos abre a los valores (Frankl, 2013). Frankl se adhirió a las ideas del filósofo y antropólogo alemán Max Scheler, quien partiendo de una base fenomenológica planteó que los valores en nuestra vida se encuentran en el mundo, por eso son objetivos, es decir, son el objeto al cual apunta la persona de forma afectiva en un acto intencional. Como personas somos seres espirituales (Scheler, 1957), esto quiere decir libres para tomar postura frente a los condicionamientos y libres para abrirnos a los valores, a todo lo que hay de valioso en nuestra vida. La persona tiende hacia el valor que le atrae y puede decidirse por él o no, ahí radica la profunda responsabilidad de cada quien en realizar los valores y con esto llenar de sentido la vida. El amor es entonces un movimiento intencional (Scheler, 2001) que nos permite captar la esencia individual - personal del Tú amado, nos abre a la posibilidad del encuentro con ese ser único y singular realizando los valores de experiencia. Pero los valores nos atraen, nunca nos empujan, por eso una relación auténtica es una relación donde prima la libre voluntad, la elección sincera y profunda que se mueve desde el amor y la responsabilidad. Por eso la experiencia de "sentirse empujado a estar con alguien" es señal de neurosis en la relación, pues lo que empuja suele ser un impulso ligado a un instinto, como de protección o seguridad emocional, por ejemplo en el caso de una pareja con co-dependencia. El amor nos brinda la maravillosa posibilidad de ver al Tú, esto es, contemplarlo en su valor esencial, por esto el amor tiene un rol propiamente descubridor en la captación de lo valioso, iluminando nuevos y más altos valores aun desconocidos (Scheler, 2001). Contrario a la idea común de que el amor nos hace ciegos, diría Frankl que más bien nos hace ver mejor, en este caso al amado, al Tú que se me presenta como otro único y legítimo, distinto a mí y a cualquiera, irrepetible y con una existencia singular. De aquí que para Frankl el auténtico amor solo sea posible en la monogamia, pues el amor apunta hacia una individualidad incomparable. El hecho de tener varias parejas refleja una intencionalidad difusa, una ambivalencia afectiva y una inmadurez espiritual, al no percibir lo esencial en una persona única sino buscar características en diversas personalidades. La terapéutica apunta a que las personas sean más conscientes de cómo se relacionan, qué tanto alcanzan a ver al otro, o si este está en la categoría de "bien", cuyo valor es la utilidad, como un plumón que cuando deja de pintar es reemplazado por otro que pinta mejor. La logoterapia apela al poder del espíritu humano que se manifiesta en autocomprensión y en autotrascendencia, para ser más conscientes y ver qué tanto estamos abiertos al mundo, dispuestos afectivamente ante el otro, para así tomar mejores decisiones sobre la relación.

Existen tres formas de relacionarse con el otro según Frankl (2013), dentro del contexto de pareja. Conocer esta visión nos es de mucha utilidad en el trabajo terapéutico. El psiquiatra vienés nos dice que dependiendo del nivel de madurez, no solo psicosexual sino en especial espiritual, la persona se intenciona hacia diferentes dimensiones del Tú, lo cual puede revelar en el proceso terapéutico la motivación o el propósito de la actitud personal frente al otro, como la elección de pareja y los modos de ser en la relación, ampliando la consciencia sobre qué tanto son valores los que movilizan a la persona o si es una pulsión instintiva la que empuja a estar junto a alguien, buscando satisfacer alguna necesidad o tapar algún vacío. Frankl nos refiere que la actitud más primitiva y más básica implica una orientación hacia lo que podemos llamar la "capa más externa" del ser del otro, es decir, la dimensión corporal, por lo que hablamos de una actitud sexual, donde la atracción física es lo que prima en la elección de pareja. En este nivel de relación es "la estampa física la que emana 
un encanto sexual y hace nacer el mismo impulso en el otro sexualmente predispuesto" (Frankl, 2013 p. 199), siendo así la persona queda afectada tan solo por la exterioridad del otro y por lo tanto su interés relacional estará centrado en valores en estricto sensibles (Scheler, 2001), es decir, relacionados al agrado y al placer. En este tipo de relación existe una escasa compenetración a un nivel más allá del corporal, y el Tú se convierte en un objeto satisfactor de una necesidad sexual. La inmadurez se muestra en el afán de poseer al otro, en un tener, que limita la visión espiritual. Podemos encontrar esta actitud en relaciones adolescentes donde podríamos decir que es algo propio del desarrollo, pero también en relaciones neuróticas donde la búsqueda y obtención de placer son parte de un modo de ser inauténtico cuyo propósito es aliviar algún malestar psicofísico, en especial relacionado a la toma de responsabilidad sobre la propia vida. Por ejemplo, alguien que para escapar de la soledad recurre a diversas parejas sexuales, a través del placer se distrae de lo realmente importante y que le demanda respuesta en su vida. Es decir, un escape de la responsabilidad y una huida frente a la angustia que ser libre conlleva. Ya decía Frankl que solo un ser libre puede sentir angustia (Frankl, 2008), y una forma de evadirla es orientándose hacia el placer y el poder (Frankl, 2002), para así no sentir el peso existencial de una vida vacía de sentido. Efectivamente cuando la persona se desvía de lo realmente significativo aparece lo que llamamos voluntad de placer. Las relaciones orientadas de esta manera tienden a ser en el fondo insatisfactorias, ya que el placer pasa de manera fugaz, es efímero, carente de profundidad afectiva, por lo que esta actitud termina desgastando a la pareja agravando su situación existencial.

La segunda actitud frente al otro es una elevación de nivel, puesto que según Frankl se orienta a la siguiente dimensión humana, a la siguiente capa existencial, es decir, la personalidad. Aquí la intencionalidad del enamorado penetra en la estructura de la pareja más allá de la corporalidad y el interés sexual, apuntando hacia las características de su forma de ser, hacia lo que el Tú tiene en sus facetas, lo que Frankl llama lo erótico. Siendo así la persona enamorada se intenciona hacia lo psicológico y anímico del otro, "conmovido en su emotividad psíquica por la psique original de la otra persona, por determinados rasgos de carácter que se manifiestan en ella" (Frankl, 2013 p. 200), es decir, se orienta hacia un determinado tipo de personalidad. De ahí la famosa pregunta ¿cuál es tu tipo de hombre o de mujer? Y quien responde mencionará ciertas características del modo de ser, aquellas que le complazcan y que quizá calcen con sus propias expectativas, aquel tipo de personalidad con el cual vivir la relación perfecta. Curiosamente quien busca o tiene predisposición por tal o cual tipo de personalidad solo mencionará características que se tienen, pero nunca a una persona única y singular. Podríamos considerar que tanto el primer como el segundo nivel de relación son lo que llamamos "enamoramiento" (Frankl, 2013), que apunta a los fenómenos corporales y anímicos, pero no alcanza a contemplar a la persona única e irrepetible que constituye al auténtico ser amado, más allá de lo que este tiene como características psicológicas y anímicas, sino a quien es como persona espiritual.

Precisamente este vendría a ser el tercer nivel de relación, el más elevado y a la vez profundo, en el cual la intencionalidad del amante penetra más allá del "ropaje externo" y llega hasta el "meollo espiritual" del Tú amado, encontrándose con su esencia personal individual, con su unicidad y su singularidad, esto es, con el hecho que su vida se da una sola vez (Frankl, 2013). El Tú cobra sentido en la vida del amante en la vivencia de la relación, pues el amor moviliza la vista hacia la irrepetibilidad del amado, hacia su ser insustituible. El amante así reconoce que no hay ningún otro como esa persona, ya que su mirada no se queda en las capas más externas del otro (corporalidad y personalidad) donde prima el placer, entendido también como distensión psicológica, sino que alcanza realmente al otro, a quien ese otro es. En este sentido la sexualidad deja de ser solo medio para la satisfacción de impulsos instintivos y naturales para convertirse en vehículo para la manifestación del amor (Frankl, 2004). Se pasa así de la obtención de placer a la realización de valores. El otro es visto en su real dimensión de unicidad y dignidad esencial. Podríamos decir además que toda pareja madura espiritualmente puede orientarse también, por así decirlo, hacia las capas externas del cuerpo y la psique, sin perder de vista al ser amado como un Tú único y singular. La satisfacción existencial o el sentido del vínculo no se limitan por esta orientación sino más bien lo 
enriquecen. Sin embargo el amor auténtico garantiza el estar junto al otro amado más allá del paso del tiempo y sus cambios físicos y de carácter, incluso más allá de su muerte o su ausencia física.

El abordaje terapéutico ha de buscar comprender entonces la forma como la pareja se relaciona, por decirlo así, en qué nivel de relación se encuentran en mayor o menor medida, explorando las actitudes frente al otro como manifestación del nivel de madurez psico - sexual - espiritual. Es decir, qué tan madura es la pareja, que tanto alcanzan a ver más allá de sí mismos, que tanto logran ver al otro como un legítimo otro que piensa, siente, actúa, anhela o necesita de una forma única y distinta. El autodistanciamiento como capacidad para observarse a uno mismo en situación se despliega para una mayor comprensión y la autotrascendencia como capacidad para ir más allá de uno mismo hacia el otro amado se manifiesta como un velo que cae y permite conocer y comprender mejor al otro, de una forma más realista. La pareja puede asumir una postura ante todo esto, es decir, elegir cómo quieren relacionarse ahora, asumiendo una mayor responsabilidad en la relación y atreviéndose a abrirse al mundo para ver más al Tú y para dejarse ver también. Cuando la espiritualidad está restringida las manifestaciones propiamente humanas quedan limitadas, orientando la voluntad hacia el placer y el poder. La pareja se mueve entonces dentro de las dos capas externas, no logran ver a un ser único con el cual encontrarse sino un objeto satisfactor de impulsos sexuales (nivel de corporalidad) o en otros casos se orientan hacia un tipo de personalidad que les cautiva (nivel psicológico - anímico). Podemos observar que esta inmadurez espiritual conlleva a una cosificación del Tú donde queda reducido a simple medio para un fin. La logoterapia busca, a través de la relación entre el terapeuta y la pareja, des - restringir lo espiritual en cada uno para así elegir quizá modos de ser - con - el - otro más sanos y auténticos. Esto no significa que sea un objetivo que la pareja continúe sino que logren verse mejor a sí mismos y mutuamente para así tomar decisión. No son pocos los casos donde la pareja decide terminar luego de desplegar la espiritualidad, pues descubren que sus motivaciones no eran por valores sino empujadas por algún instinto, necesidad o vacío, dando por terminada la relación y abriéndose a la experiencia de la soledad, por ejemplo.

\section{La comunicación como fundamento existencial de la relación}

Este es un punto clave para plantear una terapéutica de las relaciones de pareja desde una perspectiva humanista - existencial - fenomenológica, orientada a los valores y que apela y revela lo espiritual en el ser humano, como lo es la logoterapia. Hemos revisado que para Frankl la persona es siempre una relación, una situación relacional, un ser - con - otros que nunca existe en aislamiento. Esto nos invita a pensar en el fenómeno comunicación como un fundamento existencial, una acción que es un movimiento intencional hacia el Tú, un reconocer al otro en su libertad y posibilidades, reconociéndonos también en la apertura a todo lo valioso y riesgoso que puede tener el encuentro auténtico con ese otro. Pero esta comunicación auténtica necesita de una responsabilidad, puesto que comunicarse es expresarse y esto es una elección propia y personal inalienable, un emerger genuino al mundo donde otro aguarda para ser encontrado, ser conocido y conocer también a quien se abre. La comunicación es entonces un asunto de atrevimiento, de arriesgarse en la búsqueda de la verdad junto con el Tú, pues "no podemos tener en posesión objetiva la verdad, como la única verdad eterna, y porque la ex - sistencia es solo con otra ex sistencia, la comunicación es la forma de revelarse la verdad en el tiempo" (Jaspers, 2003 p. 48).

La comunicación es el sustento de la relación de pareja, siempre que esta sea auténtica, propia y trascendente. Cuando la comunicación es inauténtica, es decir, alejada de lo verdadero, huidiza, indirecta, la intencionalidad no apunta con claridad hacia el otro, y el contenido vivencial del amante, el cual es un mensaje existente, queda atrapado en la inmanencia, sin dar el salto, evidenciando un espacio entre los amantes que es percibido como una gran distancia. En estas circunstancias la pareja puede tender a gritarse, puesto que no logran salvar la distancia existencial que se les presenta, ante la desesperación de no lograr encontrarse y comprenderse. La comunicación auténtica se torna necesaria para el encuentro, para la co - construcción del proyecto mutuo, es un puente tendido hacia el otro, arriesgándose a la apertura que atemoriza por la desnudez, pero es requisito para una vida sana de pareja, porque "el hombre encuentra en el mundo al otro como la única realidad con la cual 
puede unirse entendiéndose y con confianza" (Jaspers, 2003 p. 49).

En el proceso terapéutico desplegaremos el diálogo socrático para favorecer la consciencia en la pareja respecto a cómo se comunican, analizando la actitud frente al otro y los modos a través de los cuales no se arriesgan a una comunicación auténtica. Temores profundos y reacciones de huida o de lucha frente al Tú caracterizan a esta inautenticidad, y que son esfuerzos por cuidarse emocionalmente. Por eso cuando la comunicación es inauténtica el otro es percibido como una amenaza, por lo que dejarse ver es un riesgo, así como ver la realidad del otro. La logoterapia es traer claridad para que así la pareja elija qué hacer respecto a su modo de expresión, y quizá tomen la decisión de aventurarse al encuentro del otro con todo y la angustia de responder por sí mismos ante su situación relacional.

Así podemos encontrar que para evitar conflictos alguien calla y cede. Al no apropiarse de su situación, elude el dar respuesta ante lo que la vida le plantea y no se arriesga a ser sí mismo con la pareja. No se permite abrirse, dejarse ver, ni ver más al otro, lo cual llegaría con la elección de expresarse genuinamente. Esto se vuelve demasiado riesgo, por lo que la elección es quedarse "adentro", quizá mostrando algo que disfrace el momento. De esta forma se evita el conflicto pero se paga el precio de la insatisfacción por una relación inauténtica, cuando incluso el conflicto es la inevitable situación del encuentro entre dos personas distintas. El reto existencial junto a otro es precisamente ser - con - un - otro que es diferente. Otra persona puede por ejemplo mostrarse hostil y agresiva en la comunicación con el otro, y aunque haya expresión, esta no es genuina sino movilizada por el instinto y la necesidad de respeto, sin autocomprensión clara respecto al para qué del comportamiento, cuidándose emocionalmente a través de esta forma de ser. Lamentablemente el miedo anula al respeto y la relación cae inevitablemente en la neurosis al no haber autenticidad. Solo en la apertura hacia el otro es que la relación cobra sentido, al experimentar lo que Frankl llama valores de experiencia (Frankl, 2001), la recepción del amor por parte del amante y que proviene del amado. Pero esta dación y recepción afectiva solo puede darse en la comunicación auténtica, que proviene de una elección responsable. Por eso el amor es un acto intencional y por ende un acto espiritual. Una tarea terapéutica es trabajar en construir (o reconstruir) el puente.

\section{Autenticidad e inautenticidad en la comunicación en la pareja}

Hemos visto que esta autenticidad es una cuestión de riesgo. A lo largo del tiempo vamos experimentando diversos sucesos que nos van marcando emocionalmente, tanto favorablemente como no, constituyéndose en vivencias que nos acompañan hasta la actualidad. Muchas de estas vivencias se originan por golpes de la vida, grandes golpes o pequeños golpes en la misma zona afectiva, quizá en la misma zona frágil, generándose moretones psicológico - emocionales. Proteger los moretones es algo propio del ser humano, movilizado por el principio de placer, evitando el dolor que el mundo podría ocasionar si tales moretones quedasen expuestos. La personalidad puede ser entonces el instrumento no solo para manifestarse como ser espiritual sino también instrumento de cuidado sobre la propia estabilidad emocional, solo que a veces ese cuidado es tal que la persona termina cerrándose, dejando de estar dispuesta afectivamente ante el mundo (Scheler, 2001). Y esto implica cerrarse ante el otro que se presenta como una amenaza quizá a algunos de esos grandes moretones que el amante esconde con recelo. A veces huyendo, a veces luchando, a veces dejándose al abandono, intentando renunciar a su propia libertad, la persona se cuida y con esto inhibe su capacidad de amar, puesto que el amor es un sentimiento intencional que trasciende al Yo para captar y acoger al Tú en toda su profundidad y esencia. Y como el amor es además el movimiento que nos abre a los valores, este estar cerrado tiene como consecuencia una falta de percepción de todo lo valioso que el encuentro con el otro podría traer y que la persona intuye a lo lejos, en la otra orilla de la relación, pero nadar ese tramo representa quizá uno de los más angustiantes riesgos. La terapia es un constante preguntar y cuestionar las formas de cuidarse que impliquen perderse de lo valioso con el otro, sin animar a nada, sin empujar ninguna elección, solo facilitando mediante el diálogo que se clarifique la verdad de cada quien en la co construcción de una verdad relacional. La terapia es un aprender a verse mutuamente, a escucharse, a arriesgarse a salir un poco más al encuentro del Tú. 
Ver y dejarse ver es cosa de comunicación y esta se basa en la autenticidad. Una personalidad auténtica es permeable al mundo (Martínez, 2011), permite que la persona espiritual se manifieste y el Yo alcance al Tú. Pero tal responsabilidad pasa por sentir angustia. Decía Kierkegaard que la angustia es el vértigo de la libertad (Kierkegaard, 1984), y que es necesario sentirla y acogerla para así dar el salto hacia lo incierto, hacia lo nuevo que no se conoce, pero una nada en la que se intuyen a lo lejos posibilidades de valor. Dejar la inautenticidad y dar el salto hacia lo auténtico pasa por asumir la responsabilidad en la relación, pues no hay verdadero conocimiento del otro si no hay la voluntad de retirar toda barrera, toda estrategia de cuidado que restrinja de paso la realización del sentido del vínculo, del sentido que trae la relación con el otro. Con justa razón menciona Buber: "en el yo - tú estamos a intemperie, por eso nos angustiamos, al no sentir el techo que nos protegía, pero ese techo nos impedía ver las estrellas" (Buber, 1979). Tal parece que la angustia y el amor van de la mano, y el amor se constituye en un acto intencional y afectivo, una actitud movilizada desde la libertad. En la terapia la pareja puede atreverse a retirar el "techo" y quedarse "a la intemperie", asumiendo la angustia propia de que están decidiendo y nadie lo podría hacer por ellos mismos, entonces depende de ellos, en su ser relación, la vivencia del sentido de su vínculo. Sin techo les caerá la lluvia, pero quizá mojarse juntos sea una gran fuente de valores y sentido, mientras miran uno junto al otro esas estrellas que antes no veían.

\section{Decir, pedir y preguntar: claves para una comunicación auténtica}

En la terapia podemos trabajar en base a tres premisas indispensables para que pueda desplegarse una comunicación auténtica. Toda relación sana implica que la pareja se arriesgue a abrirse y salir al encuentro del otro, verlo y dejarse ver, y esto puede darse si se atreven a decir, pedir y preguntar, tres cosas que cuestan, porque implica quitar el techo, abrir la puerta, expresarse genuinamente y quedar a la intemperie. Al decir, el amante expresa su verdad al amado, pone "sobre la mesa" su sentir original, su pensar, sus deseos, sufrimiento, expectativas, necesidades, alegrías e insatisfacciones en relación al otro, y si bien se arriesga, también puede encontrarse con él. Al poner su ser sobre la mesa ambos pueden ver mejor aquello, en la posibilidad de que el Tú conozca un poco más del Yo cada vez y viceversa. Una pareja jamás termina de conocerse, lo cual es un maravilloso aliciente para comunicarse auténticamente. Al pedir, el amante solicita al amado algo y se expone, queda vulnerable ante su respuesta, pero es un riesgo que hay que correr para alcanzarlo y conocerlo, así como la profunda responsabilidad de asumir lo que se necesita del otro y de tender un puente. Ya decía el sabio Hillel: "si no lo hago yo, ¿quién?". Y Preguntar es un arte que hay que desarrollar para seguir la premisa socrática por excelencia de conocerse, en este caso mutuamente, el uno al otro en lo más verdadero, y esto trae de forma inevitable un mayor conocimiento de sí mismos. Además no hay nada más amoroso y respetuoso que querer saber del amado, de querer conocerle siempre y penetrar así cada vez más en la profundidad de su esencia, es decir, de su unicidad y su ser siempre posibilidad y novedad. La terapia moviliza estas tres acciones, primero explorando las posibles formas de restricción de lo espiritual en términos de autodistanciamiento (no ser consciente de la forma de ser y no asumir responsabilidad sobre su situación) y autotrascendencia (no intencionarse hacia el otro) para luego apelar al poder del espíritu y tomar postura ante la limitación que se genera y la intuición de posibles valores, buscando elecciones más satisfactorias y con más sentido.

\section{Inautenticidad en las relaciones de pareja: las neurosis}

Una relación de pareja implica una diversidad de aspectos que la tornan en algo muy complejo. La elección inicial de la pareja, la disposición afectiva hacia el otro, la forma de comunicarse y los modos que cada uno encuentra para cuidarse del Tú son parte de la personalidad de los amantes. La estructura de personalidad es algo que cada uno de alguna manera trae a la relación desde su propia historia, poniéndose de manifiesto en el vínculo. Muchas veces esta personalidad se ha cristalizado en el tiempo como un modo de ser inauténtico (Martínez, 2011), una personalidad rígida impermeable al mundo, que impide a la persona manifestarse y encontrarse con un otro de forma verdadera. Así podemos encontrar, entre otras, las relaciones donde prima la dependencia (orientación hacia el placer) y aquellas donde prima la obsesión y el control (orientación hacia el poder). 
En las relaciones dependientes la forma de ser con el otro se basa en la inautenticidad, en una profunda falta de responsabilidad sobre la propia vida que conlleva a una gran insatisfacción, con fuertes sentimientos ambivalentes y un sufrimiento innecesario. Estas relaciones se caracterizan por un fuerte enganche mutuo, pues donde alguien depende del otro para sentirse acompañado o amado, hay un otro que necesita sentir que acompaña o ama, es decir, ambos se cuidan emocionalmente sin ser conscientes de ello a través de la relación. Al depender uno de otro no se da una relación Yo - Tú, sino Yo - ello (Buber, 1979), donde el otro es visto en su utilidad, dejando de contemplar el valor esencial que realmente le corresponde, que es la dignidad propia de ser único y singular. Depender del otro para existir implica un no poder valerse por sí mismo afectivamente, y esto no quiere decir ser autosuficiente sino interdependiente, es decir, saber alcanzar al Tú en la comunicación para pedir auténticamente lo que hace falta. En la dependencia los amantes no logran ser - con - el otro, por lo que no puede darse la co-construcción del proyecto juntos, porque no tienen un proyecto propio, al no apropiarse de sí mismos. Decía Frankl (2008) que una comunidad está constituida por personas que viven validando la singularidad de sus existencias, desde la afirmación profunda del ser propio, asumiendo su responsabilidad y ejerciendo su propia libertad. Cuando no hay esta autenticidad individual se cae en el colectivismo, que es una forma de neurosis de masa, en el caso de la relación de pareja, una neurosis vincular entre dos personas que se funden entre ellas sin distinguirse en su unicidad y por ende en sus diferencias, perdidos de sí mismos intentando encontrarse en el otro, dependiendo del otro para tener un sentido vital. La falta de un espacio propio y el temor a la soledad conllevan a una profunda desesperación, ante la posibilidad de perder al otro. Pero no se trata necesariamente de un temor como sentimiento intencional (Scheler, 2001) que apunta un valor en peligro, sino ante la pérdida de aquello que resulta útil para no enfrentar la vida, es decir, de lo que la otra persona significa. Entonces mantener la relación a toda costa se vuelve un imperativo. Y para lograr conservar el vínculo se recurre a constantes manipulaciones a través de una comunicación inauténtica donde no hay apertura ni confianza, sino más bien constantes chantajes emocionales para corroborar cuan amados son por el Tú, o acomodándose a este, algo que no es tan complicado (aunque sí muy insatisfactorio) tomando en cuenta la falta de lo propio. Los resentimientos ocultos y expresados de forma pasivo agresiva suelen ser comunes, y ante la gran falta de una comunicación auténtica la pareja cae en un esquema viciado lleno de sufrimiento e impotencia, sin poder encontrarse ni conocerse, ni respetarse en realidad. Ya decía Kierkegaard que la persona desespera por querer ser ella misma, pero también desespera por no querer ser ella misma (Kierkegaard, 2013). Dar el salto a lo original es angustiante, ser - con - el - otro requiere de coraje existencial, encargarse de lo propio contando con el Tú como confidente, arriesgando toda seguridad, es un asunto de libertad y responsabilidad.

La terapia de orientación logoterapéutica con la pareja buscará a través del diálogo socrático el despliegue de la libertad en términos del autodistanciamiento necesario para clarificar la propia existencia, apelando al poder de oposición del espíritu (Frankl, 2007) para tomar una postura, un cambio de actitud frente a la propia vida y frente al otro, asumiendo el riesgo de tomar las propias riendas y apelando a la persona espiritual en términos de autotrascendencia para así atreverse a abrirse al mundo, un mundo donde el Tú espera en toda su unicidad y valor para encontrarse y conocerse un poco más de verdad. Explorar y favorecer la comunicación existencial es parte del proceso. Animarse a decirle al otro, a preguntarle y a pedirle son posibilidades para un mayor encuentro, validando el riesgo de entrar en conflicto, enfrentando directamente el miedo al abandono o a la soledad, apoyándose en el Tú de forma genuina, dejándose ver y conocer. Solo conociéndose mutuamente pueden amarse, pues no se ama lo que no se conoce. Construir juntos un proyecto nace de que cada uno construya el suyo propio. La vivencia del propio espacio, el permiso para las propias decisiones y el aprender a mirar al otro en su ser distinto para llegar a acuerdos sin inundarse emocionalmente o sin huir del momento son apelaciones a la espiritualidad que el proceso conlleva.

En las relaciones obsesivas se dan intentos desesperados por controlar la relación, por lo que se aprecia una voluntad de poder exacerbada, y opera mediante una intensa búsqueda de perfección, donde 
los conflictos son evitados a como dé lugar para no sentir que la relación fracasa y que la vida misma es un fracaso. Puede haber relaciones donde ambos presentan rasgos obsesivos o sólo uno de los miembros de la pareja, siendo así los defectos del otro son siempre dados a notar en los intentos por mantener el control. Quizá una educación estricta (Martínez, 2011), muchas exigencias sobre sus capacidades sumadas a vivencias de insuficiencia crean en el amante el perfil obsesivo. El otro es mirado no como a un otro legítimo sino como a un objeto a través del cual evitar cualquier sentimiento de insuficiencia o incapacidad. Que el Tú tenga la razón, o que tenga independencia de pensamiento puede ser un terrible riesgo, y en este esquema vive en una constante lucha por su autonomía. Esto conlleva a una gran insatisfacción en la pareja al no lograr comprenderse, ya decía Elisabeth Lukas que en la neurosis se da una incapacidad para amar (Lukas, 2004). El afecto es dado por gotas, la emocionalidad se limita y la persona no se expresa en cuanto tal con el otro. Incluso la sexualidad es vivida como un deber (Martínez, 2011), y toda actividad en pareja es controlada mediante reglas rígidas y sistematizaciones. Los celos intensos, las actitudes posesivas y las constantes evaluaciones y críticas son comunes, ya que cualquier posibilidad de descontrol y fracaso es vivida como un terrible peligro existencial. La pareja no se permite fallar en algo, o llegar a discordar, pues todo tiene que estar bien. Así se pierde la pasión por la pérdida de espontaneidad, en el constante intento porque todo esté bajo control.

La psicoterapia de pareja orientada desde la logoterapia busca, por medio del diálogo, que se exprese la persona espiritual en términos de autodistanciamiento, para así tomar consciencia de los modos de ser inauténticos que traen una gran insatisfacción, arriesgándose al desacuerdo, permitiéndose fallar de vez en cuando, atreviéndose a sentir la angustia de soltar la vida del otro, validándolo como un Tú diferente e independiente. La dificultad por comprender el punto de vista o el sentir del otro es trabajada de tal forma que las personas se autotrasciendan y se permitan verse un poco mejor, resonando afectivamente respecto a lo que sienten, aceptando de pronto no tener la razón en todo, arriesgándose a una forma de ser distinta donde lo humano se revela en su dimensión angustiante y al mismo tiempo satisfactoria. La derreflexión frankleana (Frankl, 2008) cobra fuerza buscando que los miembros de la pareja recuperen la espontaneidad dejando de "tomarse tan en serio" como diría Frankl y orientándose hacia lo realmente importante en la relación y que implica el proyecto en común, ese estar uno - junto - al - otro que sustenta el vínculo y la comunidad de a dos que representa la relación.

\section{El diálogo socrático de a tres: comunicación y encuentro en la terapia con parejas}

Encontrase con una pareja en un contexto terapéutico desde una orientación logoterapéutica requiere la puesta en forma de una actitud especial, de una disposición afectiva que se sustenta en el amor y en la ignorancia, en el profundo afecto intencional que apunta a esa relación que se presenta, contemplándola como algo nuevo, distinto, con dos personas que son únicas y diferentes y conforman así mismo un vínculo único y diferente a cualquier otro vínculo, a cualquier otra pareja. Esta es una invitación a conocer la relación, a buscar juntos que comprender su mundo vincular, dejando las teorías de lado, así como las interpretaciones rígidas y los prejuicios. La mirada del logoterapeuta busca ser una mirada humana y que humaniza los vínculos donde a veces se cae en la cosificación. Así mismo el terapeuta puede caer en el tecnicismo y volver el proceso un mecanicismo, olvidándose de las personas que conforman ese "nosotros", ese entre sobre el cual hay que poner la mirada.

En logoterapia entendemos que el principal agente de cambio es el vínculo mismo. La persona del terapeuta sumada a las personas en la relación de pareja configuran el proceso y en la calidad de esta relación se abre la posibilidad de una terapia satisfactoria para todos. Se trata de poner el énfasis entonces en la manera de relacionarse, de comunicarse entre los tres y de aquí van surgiendo las verdades, pues como diría Jaspers inspirado en Sócrates: la verdad se hace patente en el diálogo (Jaspers, 2013). Precisamente este es un diálogo socrático, fundado en una actitud socrática donde la ignorancia es el punto de partida como actitud existencial para llegar al conocimiento. La ignorancia socrática parte del terapeuta pero se encarna en la pareja cuando descubren que sus verdades no eran absolutas sino que existe otra verdad que es la 
del otro y otras verdades que pueden ser propias, que se revelan con el despliegue espiritual y que movilizan a cambiar el rumbo de las cosas, quizá para mejor. Es la fenomenología de la que nos habla Frankl, pues recurrimos a una "investigación fenomenológica" de las vivencias descritas por la pareja en lo emocional, cognitivo y conductual en la relación, intentando una comprensión común. El terapeuta ha de ser cauteloso y descubrirse pre juzgando, teorizando, interpretando a la pareja y sus experiencias, es decir, intentando explicarse las cosas (lo que lleva a explicarle a la pareja) para abrirse a la posibilidad del asombro frente a los consultantes. Sin duda se requiere cuestionar cómo conocemos a las personas para atreverse a conocerlas un poco más o mejor. Es la invitación a que la pareja también se de ese permiso mutuamente.

Los momentos del proceso terapéutico: el setting o el encuadre y las sesiones

Todo proceso psicoterapéutico requiere de un encuadre, una forma de disponerse al encuentro, sumado al contexto espacial y posicional, así como ciertas condiciones para el desarrollo de la terapia. En la terapia de pareja de orientación logoterapéutica el encuadre implica la consideración de la interacción entre los elementos principales de la relación terapéutica, siendo estos el terapeuta y la pareja, y lo que pasa entre ellos, donde el elemento privilegiado ha de ser la comunicación. La primera sesión puede ser informativa - descriptiva de forma individual inicialmente, para así escuchar la percepción de cada persona, pues a veces suelen ocultar elementos importantes en presencia del otro y que hay que indagar al comienzo, con preguntas como: ¿qué es lo que según tú los trae por aquí?, ¿cuál es tu percepción $o$ tu sentir sobre el problema que los trae?, ¿qué tanto sentido tiene para ti la relación?, ¿encuentras aspectos valiosos en la relación?, o ¿qué es lo que quieres tú respecto a tu relación al venir aquí? A veces ambos quieren lo mismo: mejorar la relación. Otras veces uno de ellos no sabe cómo decirle al otro que ya no quiere continuar el vínculo. Este encuadre inicial revela el nivel de apertura y confianza que la pareja se tiene. La forma de iniciar puede ser preguntando fuera del consultorio: ¿quién de los dos quisiera entrar primero? Ahí empieza a manifestarse la manera cómo se relacionan, cómo se comunican, quien tiene un mayor poder o si hay consenso y disposición a ceder. También puede expresarse qué tanto sentido del humor despliegan, o qué tanto no se logran poner de acuerdo. En esta primera sesión el terapeuta dialoga unos veinticinco o treinta minutos con cada uno, para luego reunirse con los dos y comentarles lo que ha comprendido respecto a la percepción de cada uno y lo que cada uno quiere respecto al proceso. Solo en el caso que concuerden en por ejemplo qué quieren para la relación, se menciona a manera de motivación mutua para el cambio. Caso contrario el dilema se trabaja en las sesiones posteriores. También se puede mencionar que de aquí en adelante las sesiones serán siempre en pareja.

Cada sesión suele durar en promedio una hora o una hora con diez minutos a lo mucho, y en todo el proceso no suele haber más de doce a quince sesiones. En la segunda sesión puede disponerse las sillas o muebles formando un triangulo, donde el terapeuta puede dialogar con ambos, sin embargo luego hemos de pasar a la posición en la que quedarán el resto del proceso, es decir, frente a frente, pues recordemos que la comunicación es el fundamento de la relación y en sí la terapia es un análisis existencial de la comunicación en la pareja. Por ende han de enfrentarse para así poder revisar los modos de ser uno frente al otro y propiciar un mayor encuentro y comprensión mutuos.

Como hemos visto el diálogo socrático en parejas se basa en una actitud fenomenológica, donde como terapeutas "suspendemos" todo conocimiento previo respecto a la realidad de la pareja, ya sean teorías, juicios de valor, prejuicios, experiencias propias o cualquier saber que nos mueva a inferir e interpretar a la pareja para caer en explicaciones. Esto es de mucha ayuda si buscamos comprender la experiencia para luego sobre esa claridad las personas elijan qué hacer con su relación. Esta suspensión es entonces una abstención de todo el conocimiento, lo que en griego se denomina "epojé" (Reeder, 2011), un poner entre paréntesis todo conocimiento para quedarnos solo con lo que podemos ir experimentando en la relación con la pareja. Al hacer esta suspensión podemos describir aquello que se va manifestando en la relación terapéutica, tanto en lo afectivo, como en lo cognitivo y conductual. La descripción abre paso a la comprensión en un constante cuestionar, notando las propias interpretaciones para así volver la intencionalidad hacia la pareja, abiertos a la experiencia novedosa del encuentro. 
En un sentido de actitud también nos referimos a la ironía (del griego eironeia o un "hacerse el ignorante") como una postura de no saber que mueve la curiosidad del terapeuta y despierta en la pareja una sana inquietud y confusión que luego se traduce en comprensión mutua. La ironía remece los cimientos de las definiciones que ambos tienen respecto al otro y a sí mismos, como diría Kierkegaard, en una auténtica determinación de la subjetividad (Kierkegaard, 2000), incluso a través del sentido del humor, el cual es para Frankl un recurso del espíritu humano que emana de la libertad. Ya decía Allport que quien se ríe de sí mismo ya dio un gran paso para superar su neurosis. En este caso si la pareja aprende a recibir la ironía puede aprender a emplearla de forma tal que logren no tomarse tan en serio las cosas, con una buena dosis de autodistanciamiento y autotrascendencia. ¿En realidad esperas que ella piense exactamente como tú? La ironía confronta, sacude, como el pez torpedo socrático, donde tras el golpe todos, incluyendo el terapeuta, quedan confundidos.

\section{El transcurrir de las sesiones y el despliegue de los recursos noológicos}

Siendo una terapia de orientación frankleana buscaremos juntos, los tres, desplegar lo espiritual en términos de los recursos noológicos a través del encuentro mismo. Aquí el autodistanciamiento se da gracias a la mirada del otro, en la medida en que su mirada es validada como una legítima mirada, dando así lugar a la autotrascendencia.

Explorar qué tanto se comprenden a sí mismos es parte necesaria del proceso, para así clarificar las experiencias subjetivas en pro de una más clara intersubjetividad, preguntando acerca de la experiencia de cada uno respecto a alguna problemática que traen, analizando existencialmente cada dimensión de la experiencia, a saber lo emocional, lo cognitivo y lo conductual siempre mirando la relación y no a una persona aislada o de forma individualista. Las preguntas socráticas son preguntas fenomenológicas que invitan a la descripción más que a la interpretación, pues buscan comprensión más que explicación. ¿Qué es lo que sientes cuando esto ocurre?, ¿cómo sientes esto?, ¿qué significa esto para ti? ¿qué es lo que haces cuando eso pasa? Al explorar las dimensiones de la experiencia se abre la posibilidad de explorar el nivel de afectación del amante frente a lo valioso del Tú. Entonces el terapeuta se dirige a aquel para explorar qué tanto está abierto al otro, qué tanto lo alcanza para escucharlo más allá de los oídos de lo propio: ¿y tú qué tanto lo escuchaste?, ¿qué es lo que sientes con lo que ella siente?, ¿qué tanto validas como legítima su experiencia y su punto de vista? La comunicación es el fundamento de la relación, y la logoterapia es un análisis de la forma cómo se comunican, en este sentido, qué tan auténtica es, que tan propia, que tan directa y que tan afectiva. La responsabilidad de la expresión recae en cada uno, pues buscamos reconocer la angustia propia de asumir lo propio en la relación: nadie va a hablar por ti aquí, nadie va a expresar lo que sientes, piensas o necesitas si no eres tú. La angustia es entonces comprensible, pero en un sentido movilizador de la responsabilidad, como señal de la libertad. "Ok, la verdad es que quiero que comprendas que necesito que me abraces". Ahora el terapeuta puede dirigirse al otro para analizar existencialmente qué experimenta frente a la experiencia del amado: ¿Qué tanto alcanzas a reconocer lo que te dice?, ¿cómo sientes esto que te pide?, ¿qué le respondes?

Una comunicación auténtica es un puente que supera todo prejuicio acerca del Tú, cuestionando la mirada que tienen el uno del otro. "Él ya debería saber" o "si no le nace no tengo por qué pedírselo", resulta lo que Frankl llama reacciones neuróticas, en este caso una pasividad donde no se adueñan de la responsabilidad en la comunicación: ¿Y si se lo dices directamente y no a mi?, o ¿se lo has pedido?, suelen ser preguntas interesantes, así como aquellas que exploran la angustia como ¿cuál es el riesgo de encontrarte con ella?, ¿qué pones en juego si le preguntas?, o explorando las formas de ser que cuidan lo valioso y frágil en lo emocional: ¿qué es lo que tanto cuidas en tu corazón al no expresarle? Muchas veces es en la terapia cuando empiezan a reconocerse mutuamente, "no sabía que sentías eso", desplegando una mayor autotrascendencia al comprender mejor al otro. Así mismo una actividad inauténtica en la comunicación implica por ejemplo una comunicación hostil o dominante. La mayéutica socrática tiende aquí a confrontar: ¿para qué te muestras de esa forma con ella?, ¿qué ocurre si dejas de hacer esto?, ¿cuál es el riesgo?, así como por supuesto la confrontación con los posibles valores: ¿de qué te puedes estar perdiendo al 
mantener esta actitud? lo cual implica también analizar la insatisfacción relacional - existencial: ¿cuál es el precio que pagan por esta forma de relacionarse?

Puede ser útil trabajar ejercicios en pareja o logo - dramáticos, así como tareas para la casa, como poner en práctica lo que descubren y trabajan en las sesiones. Cada sesión puede ser abierta con un exploratorio: ¿cómo llegan hoy?, esperando a ver quién toma la primera palabra y cómo es esta dinámica. Conforme vemos que la pareja por si sola toma asiento frente a frente, podemos ir notando los cambios, en el sentido de una mayor disposición al diálogo y a la confrontación. La confrontación es el requisito para el encuentro, pues solo se encuentran quienes se disponen uno frente al otro. Las miradas son menos esquivas y la apertura se manifiesta en mayor responsabilidad sobre la comunicación y actitud de escucha, comprendiendo más al otro y dejándose ver para ser comprendidos. Así son vivenciados los valores de experiencia relacionados al amor, a una relación más genuina donde la comunicación es más auténtica y el nivel de madurez espiritual se manifiesta en una mirada mutua que supera lo físico y lo psíquico para alcanzar a la persona espiritual, al Tú verdadero como único y singular. En esta percepción y realización de valores es que podemos decir que la relación aporta sentido a la vida.

\section{REFERENCIAS}

Buber, M. (1979). Yo y Tú. Argentina: Nueva Visión.

Frankl, V. (2013). Psicoanálisis y existencialismo. México: FCE

Frankl, V. (2008). Teoría y terapia de las neurosis. España: Herder.
Frankl, V. (2007). Logoterapia y análisis existencial. España: Herder.

Frankl, V. (2004). El hombre en busca de sentido. España: Herder.

Frankl, V. (2002). La voluntad de sentido. España: Herder.

Heidegger, M. (2009). Ser y tiempo. España. Editorial Trotta.

Kierkegaard, S. (2013) Tratado de la desesperación. México: Tomo

Kierkegaard, S. (2000) Sobre el concepto de ironía. España: Trotta

Kierkegaard, S. (1984) El concepto de la angustia. Argentina: Orbis

Jaspers, K. (2013). Los grandes filósofos volumen 1. España: Tecnos

Jaspers, K. (2003). La fé filosófica. Argentina: Losada

Lukas, E. (2004). Logoterapia. Argentina: Paidós.

Martínez, Y. (2013). Filosofía existencial para terapeutas y uno que otro curioso. México: LAG

Martínez, E. (2011). Los modos de ser inauténticos. Colombia: Manual Moderno.

Reeder, H. (2011) La praxis fenomenológica de Husserl. Colombia: San Pablo

Salomón, A. y Díaz del Castillo, J. (2019) Encontrando y realizando sentido. Diálogo Socrático y ejercicios vivenciales en logoterapia. México: LAG

Scheler, M. (2001). Ética. España: Caparrós

Scheler, M. (1957). El puesto del hombre en el cosmos. Argentina: Losada.

Fecha de recepción: 16 de mayo 2019

Fecha de aceptación: 5 de junio 2019 